\title{
Comparative genetic analysis: the utility of mouse genetic systems for studying human monogenic disease
}

\author{
Peter L. Oliver · Emmanuelle Bitoun • \\ Kay E. Davies
}

Received: 24 January 2007 / Accepted: 22 March 2007/Published online: 21 May 2007

(C) Springer Science+Business Media, LLC 2007

\begin{abstract}
One of the long-term goals of mutagenesis programs in the mouse has been to generate mutant lines to facilitate the functional study of every mammalian gene. With a combination of complementary genetic approaches and advances in technology, this aim is slowly becoming a reality. One of the most important features of this strategy is the ability to identify and compare a number of mutations in the same gene, an allelic series. With the advent of gene-driven screening of mutant archives, the search for a specific series of interest is now a practical option. This review focuses on the analysis of multiple mutations from chemical mutagenesis projects in a wide variety of genes and the valuable functional information that has been obtained from these studies. Although gene knockouts and transgenics will continue to be an important resource to ascertain gene function, with a significant proportion of human diseases caused by point mutations, identifying an allelic series is becoming an equally efficient route to generating clinically relevant and functionally important mouse models.
\end{abstract}

\section{Introduction}

A fundamental aim of biology is not only to identify the normal function of genes but also to understand their role in human disease when mutated or otherwise abnormally

P. L. Oliver · E. Bitoun · K. E. Davies ( $($ )

Department of Physiology, Anatomy and Genetics,

MRC Functional Genetics Unit,

University of Oxford,

South Parks Road,

Oxford OX1 3QX, UK

e-mail: kay.davies@dpag.ox.ac.uk affected. To this end, the mouse continues to be the model organism of choice in many cases because of extensive comparative analysis of its completed genome, the availability of an increasing number of genetic manipulation techniques, and the ability to perform physiologic and behavioral tests that can be extrapolated directly to human phenotypic traits. In addition to individual research groups examining single genes, a commitment has been made in recent years to the systematic generation of mouse mutants on a large scale using various forward genetics strategies in both whole organisms and embryonic stem (ES) cells. Despite these considerable efforts, over $70 \%$ of mammalian genes still do not have a corresponding mutant line; however, this so-called "phenotype gap" is beginning to close as these projects continue, establishing a large and valuable catalog of inherited traits, their causative mutations, and importantly, multiple alleles representing each one for comparative analysis.

\section{Gene knockouts and the KOMP project}

One way to study gene function at the level of the whole organism is by examining the consequences of its inactivation. This may be achieved either by "knocking out' the relevant promoter or coding sequences, or by "knocking in" an inactivating point mutation, deletion, or truncation to disrupt the activity of the corresponding product. With a number of strategies available, including gene targeting by homologous, site-specific, or transpositional recombination, gene trapping, and RNA-mediated interference, knockout technology constitutes the most widely used approach to create loss-of-function alleles in model organisms (Chen and Soriano 2003; Kuznetsov 2003; Sangiuolo and Novelli 2004). The exploitation of inducible promoters 
and tissue-specific recombinase enzymes also allows the deletion of a gene of interest in a particular organ, cell type, and/or stage of development; such conditional and tissuespecific knockouts provide more accurate and finely tuned systems to study gene function than those generated by conventional constitutive technology (Porret et al. 2006). A combination of these approaches, in addition to the generation of multiple gene knockouts, has revolutionized the study of many fields of fundamental research, most significantly impacting developmental biology with major insights into the physiology of the hematopoietic, immune, skeletal, cardiovascular, and nervous systems (Shastry 1998; Sheahan et al. 2004; Ning et al. 2006).

Equally important, as technical advances in mapping and mutation screening have facilitated the rapid identification of genetic defects related to human disorders, targeted mutagenesis in the mouse has become an invaluable tool to model and gain mechanistic insights into the pathology and progression of these conditions. For example, disruption of the insulin receptor substrate- 2 gene has produced a good biochemical model for type- 2 diabetes (LeRoith and Gavrilova 2006). In addition constitutive heterozygous and conditional knockouts deficient for a variety of tumor suppressor genes faithfully recapitulate many of the clinical symptoms present in the corresponding human cancer predisposition syndromes, including $\mathrm{BrCal}^{+/-}$and $\mathrm{BrCa}^{+/-}$mice for familial breast cancer or $\mathrm{Ptcl}^{+/-}$mice for basal cell nevus syndrome (Ghebranious and Donehower 1998; Hakem and Mak 2001; Pazzaglia 2006). Other successes of disease modeling in the mouse from which programs of gene therapy have been initiated notably include Cftr-deficient mice for cystic fibrosis (Rosenecker et al. 2006; Snouwaert et al. 1992). These and many other knockouts have provided ideal preclinical models for diagnostic development, drug discovery, and targeted therapy testing (Walke et al. 2001; Zambrowicz and Sands 2003).

Although existing knockouts account for almost half $(12,000)$ of the known genes in the mouse genome, only $20 \%$ have been described in the literature and/or reported in public databases such as the Mouse Knockout \& Mutation Database (http://www.research.bmn.com/mkmd) or the Mouse Genome Database (http://www.informatics.jax.org). With the advent of fully annotated mouse and human genome sequences and only about 15,000 genes remaining to be disrupted, the National Institutes of Health (NIH) has recently launched the Knockout Mouse Project (KOMP), a \$52 million cooperative program over five years to generate a comprehensive public resource of systematic knockout mutations of the mouse genome in ES cells by gene targeting (http://www.nih.gov/science/models/mouse/knockout) (Austin et al. 2004). Each year approximately 500 new ES cell lines will be selected by a peer-review process for production of the corresponding knockout mice, reporter tissue expression analysis, and basic phenotyping. Depending on the findings, a number of those will undergo further characterization, including more detailed and specialized phenotyping and tissue profiling. Complementary high-throughput approaches have been applied to ES cell insertional mutagenesis, or gene trapping, and recent technological advances have extended the scope and value of this method to the generation of conditional knockout alleles in addition to targeted mutagenesis (Branda and Dymecki 2004; Cobellis et al. 2005). Recently, two major programs have been established, EUCOMM (http://www.eucomm.org) and norCOMM (http://www.norcomm.phenogenomics.ca/index.htm), with the aim of generating over 30,000 new conditional genetrap ES cell lines for analysis. In addition, these projects aim to collate and distribute compatible tissue-specific Cre recombinase lines in parallel and therefore represent a powerful resource for the selection of a desired gene knockout. By centralizing the rapid and efficient production of mouse knockouts and gene-trap lines and making them readily available to the entire scientific community, such large-scale programs will not only save considerable time and money but also will provide the basis for normalization of comparative phenotypic studies.

The seemingly perfect mouse knockout technology, however, also comes with its limitations and pitfalls. In many instances null embryos are not viable due to developmental defects, precluding the functional study of these genes at later stages of development and in the adult. This particularly applies to knockout mice of tumor suppressors which, with few exceptions, all show embryonic lethality with a distinctive pattern of organ malformations (Ghebranious and Donehower 1998). Although these mice have provided good models for the study of individual genes in embryonic development and the regulation of differentiation, apoptosis, and cell cycle control during organogenesis (Shastry, 1998), they have not necessarily been useful for the characterization of gene function in tumorigenesis. The development of conditional and tissue-specific gene-deficiency technologies mentioned above, however, has now overcome this restriction.

While mouse knockouts generally do provide very valuable information about the function of a gene in vivo, a number of reports have raised legitimate concerns as to their true value as models of human disease (Hochgeschwender and Brennan 1995; Routtenberg 1995); knockout mice often fail to recapitulate the expected clinical symptoms, sometimes producing totally unexpected, conflicting, subtle, or absent phenotypes (Elsea and Lucas 2002). Moreover, although most mouse genes do perform functions identical to their human homologs, the physiologic differences between these species may greatly 
influence the phenotypic outcome. This may notably account for differences in tissue specificity; prominent examples include $p 53$ - and $R b$-deficient mice whose tumor spectrum considerably differs from that seen in patients with Li-Fraumeni and inherited childhood retinoblastoma, respectively (Ghebranious and Donehower 1998). Another common pitfall of gene targeting is the potential disruption of transcriptional control elements that govern the expression of neighboring genes by the introduction of a selection marker from the targeting vector. This likely explains why very different phenotypes have been obtained from the disruption of the same gene using different vectors. (Gingrich and Hen 2000; Olson et al. 1996). A number of reports have also highlighted the fact that the strategies used for gene inactivation are not equivalent. To study the role of phosphoinositide 3-kinase $\gamma$ (PI3K $\gamma$ ) in cardiac function, deficient mice were generated either by using a traditional knockout strategy or by knocking in a targeted mutation that causes loss of kinase function. Surprisingly, these mice displayed different phenotypes with $\mathrm{PI} 3 \mathrm{~K} \gamma$ knockout mice showing reduced inflammatory responses and increased cardiac contractility, while the mutant PI3K $\gamma$ knockin mouse retained only the immunologic defect. Molecular studies later revealed that $\mathrm{PI} 3 \mathrm{~K} \gamma$ also functions as a scaffolding protein, thus transducing both kinase activity-dependent and -independent signaling pathways (Patrucco et al. 2004). This demonstrates that different functions of a gene may be revealed depending on the region that is inactivated.

Finally, regardless of the engineering strategy or model organism used, one major risk associated with the complete loss of function of a given gene is the establishment of compensatory mechanisms that may-at least partially-mask the effect of its inactivation. For example, despite the essential role of myoglobin in oxygen transport from erythrocytes to mitochondria, myoglobin knockout mice show normal cardiac function (Garry et al. 1998). Further studies revealed that more than half of null embryos die in utero and that those surviving have developed adaptative mechanisms to compensate for the defect in oxygen transfer (Meeson et al. 2001). In that respect, conditional knockout models offer another advantage over their constitutive counterparts as adaptive responses are unlikely to take place shortly after the knockout event. The lack of overt phenotype is especially frequent when the gene of interest belongs to a family of related proteins with some functional redundancy, and in many cases it may be necessary to create animals carrying null alleles of two or more members to obtain informative phenotypes (Kono et al. 2004).

Knockout technology has become an invaluable experimental tool for assigning gene function and modeling genetic disorders in vivo. However, it must be used with caution and some of the examples mentioned above highlight the fundamental problem posed by using genetic deficiency regarding the validity and phenotypic interpretation of knockout models; the studies are often limited to examining the compensatory effects of gene ablation as opposed to changes in the function of the gene of interest. Therefore, to address complex questions regarding gene function and regulation, complementary approaches that alter gene structure in a more subtle way must be used in conjunction with knockout technology, such as the analysis of single-point mutations and their phenotypic consequences. Such strategies may therefore be limited to the modeling of single-gene disorders as opposed to complex traits or mitochondrial or chromosomal disorders; however, approximately $10 \%$ of all human genes are currently implicated in monogenic Mendelian diseases, and this number continues to rise (Antonarakis and Beckmann 2006; Hamosh et al. 2005). Moreover, at the time of writing over two thirds of the 2300 disease genes in the Human Gene Mutation Database contain point mutations (http://www.hgmd.cf.ac.uk/ac/index.php) (Stenson et al. 2003). In addition, the fact that $75 \%$ of disorders in man are inherited in a dominant manner (McKusick 1998) indicates that both dominant and recessive mouse point mutants are vital to complement targeted knockouts and provide the most clinically relevant disease models.

\section{Phenotype- and genotype-driven approaches to generating allelic mouse mutants}

Before the advent of molecular biology, many important discoveries were derived from mutations that arrived spontaneously in inbred mouse colonies. However, to generate significant numbers of mutant mice more efficiently, a number of large-scale $N$-ethyl- $N$-nitrosourea (ENU) mutagenesis programs were instigated ten years ago (Brown and Peters 1996; Hrabe de Angelis et al. 2000; Nolan et al. 2000). Their success led to the establishment of over a dozen independent centers worldwide, each with particular skills and interests and with the aim to standardize procedures and share resources (summarized in Table 1 in Cordes 2005). Details of these strategies and variations in the breeding schemes have been reviewed extensively elsewhere (Brown and Balling 2001; Hrabe de Angelis and Balling 1998; Justice 2000). Initially, these centers have concentrated on a phenotype-driven approach, in which mutant progeny are screened for abnormalities using a simple yet quantitative assessment of physiology and behavior in combination with more focused phenotyping methods for a specific trait or organ of interest (Keays and Nolan 2003; Rogers et al. 1997; Thaung et al. 2002). Once inheritance of the phenotype is confimed, 
Table 1 Examples of characterized allelic series ( $>3$ members) generated by ENU mutagenesis

\begin{tabular}{|c|c|c|c|}
\hline Gene & $\begin{array}{l}\text { No. of sequenced } \\
\text { ENU mutants }\end{array}$ & Type of mutations & References \\
\hline Bone morphogenic protein-5 (Bmp5) & 11 & $\begin{array}{l}6 \text { missense } \\
2 \text { nonsense } \\
3 \text { splicing }\end{array}$ & Marker et al. 1997 \\
\hline $\begin{array}{l}\text { Chromodomain helicase } \\
\text { DNA-binding protein } 7 \text { (Chd7) }\end{array}$ & 9 & $\begin{array}{l}6 \text { nonsense } \\
3 \text { splicing }\end{array}$ & $\begin{array}{l}\text { Kiernan et al. 2002; } \\
\text { Bosman et al. } 2005\end{array}$ \\
\hline Type IV procollagen a1 (Col4al) & 9 & 9 missense & Favor et al. 2007 \\
\hline Type IV procollagen a2 (Col4a2) & 3 & 3 missense & Favor et al. 2007 \\
\hline Gamma-E crystallin (Cryge) & 4 & $\begin{array}{l}2 \text { missense } \\
1 \text { splicing } \\
1 \text { disruption of start codon, } \\
\text { novel protein expressed }\end{array}$ & Graw et al. 2001, 2002, 2004 \\
\hline Dystrophin $(D m d)$ & 4 & $\begin{array}{l}1 \text { nonsense } \\
3 \text { splicing }\end{array}$ & Im et al. 1996 \\
\hline Enamelin (Enam) & 3 & $\begin{array}{l}2 \text { missense } \\
1 \text { splicing }\end{array}$ & Masuya et al. 2007 \\
\hline Glucokinase $(G k)$ & 12 & $\begin{array}{l}7 \text { missense } \\
2 \text { nonsense } \\
3 \text { splicing }\end{array}$ & Inoue et al. 2004; Toye et al. 2004 \\
\hline Glucose phosphatase isomerase (Gpi1) & 4 & $\begin{array}{l}3 \text { missense } \\
1 \text { splicing }\end{array}$ & Pearce et al. 1995 \\
\hline G protein-coupled receptor 33 (Gpr33) & 5 & 5 missense & Grosse et al. 2006 \\
\hline cGMP-phosphodiesterase 6b (Pde6b) & 7 & $\begin{array}{l}2 \text { missense } \\
3 \text { nonsense } \\
2 \text { splicing }\end{array}$ & $\begin{array}{l}\text { Thaung et al. 2002; } \\
\text { Hart et al. } 2005\end{array}$ \\
\hline Lactate dehydrogenase $(L d h 1)$ & 5 & $\begin{array}{l}4 \text { missense } \\
1 \text { splicing }\end{array}$ & $\begin{array}{l}\text { Sandulache et al. } 1994 ; \\
\text { Pretsch et al. } 1998\end{array}$ \\
\hline Melanocortin-3 receptor $(M c 3 r)$ & 3 & 3 missense & Grosse et al. 2006 \\
\hline Malnocortin-4 receptor $(M c 4 r)$ & 7 & 7 missense & $\begin{array}{l}\text { Grosse et al. 2006; } \\
\text { Meehan et al. } 2006\end{array}$ \\
\hline Mammal-fish-conserved-sequence 1 (MFSC1) & 3 & 3 missense & Masuya et al. 2007 \\
\hline Myosin-Va $(M y o 5 a)$ & 10 & $\begin{array}{l}8 \text { missense } \\
2 \text { splicing }\end{array}$ & Huang et al. 1998a, 1998b \\
\hline Myosin-VIIa $(M y o 7 a)$ & 4 & $\begin{array}{l}1 \text { missense } \\
2 \text { nonsense } \\
1 \text { splicing }\end{array}$ & Mburu et al. 1997 \\
\hline Paired box gene 6 (Рax 6$)$ & 14 & $\begin{array}{l}4 \text { missense } \\
5 \text { nonsense } \\
3 \text { splice } \\
1 \text { insertion } \\
1 \text { disruption of Kozak sequence }\end{array}$ & $\begin{array}{l}\text { Favor 1983, 1986; } \\
\text { Favor and Neuhauser-Klaus 2000; } \\
\text { Favor et al. 2001; } \\
\text { Thaung et al. 2002; } \\
\text { Graw et al. } 2005\end{array}$ \\
\hline Peripheral myelin protein $22($ Pmp22) & 3 & $\begin{array}{l}2 \text { missense } \\
1 \text { nonsense }\end{array}$ & Isaacs et al. 2000, 2002 \\
\hline Quaking QKI protein $(Q k)$ & $\begin{array}{l}3 \text { (plus } 2 \\
\quad \text { unknown) }\end{array}$ & $\begin{array}{l}2 \text { missense } \\
1 \text { splicing }\end{array}$ & $\begin{array}{l}\text { Justice and Bode } 1988 ; \\
\quad \text { Noveroske et al. } 2005\end{array}$ \\
\hline Sodium channel $\mathrm{Na}_{\mathrm{v}} 1.6(\operatorname{Scn} 8 a)$ & 3 & 3 missense & Buchner et al. 2004 \\
\hline $\begin{array}{l}\text { Mothers against decapentaplegic, drosophila, } \\
\text { homolog of, } 4 \text { (Smad4) }\end{array}$ & 4 & $\begin{array}{l}2 \text { missense } \\
2 \text { splicing }\end{array}$ & $\begin{array}{l}\text { Vivian et al. 2002; } \\
\text { Chen et al. } 2006\end{array}$ \\
\hline Triosephosphatase isomerase (Tpi) & 4 & $\begin{array}{l}3 \text { missense } \\
1 \text { nonsense }\end{array}$ & Zingg et al. 1995 \\
\hline
\end{tabular}


mutant lines of interest are then analyzed in more detail and the causative mutation is identified by positional cloning.

One advantage of this approach over targeted mutagenesis is it can create a range of mutations: hypomorphic (reduced amount of gene product), hypermorphic (increased amount of gene product), and neomorphic (altered function) alleles, in addition to those that are null (loss of function), facilitating the identification of novel functions for known genes. Such a phenomenon was recently illustrated by our own studies where the identification of a stabilizing gain-of-function point mutation in the mixedlineage leukemia fusion partner $A f 4$, the cause for the neurodegeneration in the ataxic mouse mutant robotic, revealed a new role for this gene in the central nervous system otherwise unpredictable from the phenotypic presentation of the Af4 knockout mouse (Bitoun and Davies 2005; Bitoun et al. 2007; Isnard et al. 2000; Isaacs et al. 2003; Oliver et al. 2004).

The random nature of ENU also means that mutiple mutations in the same gene, an allelic series, may occur in independent lines. A combination of such mutants is therefore more likely to provide information related to gene dosage, or the identification of functionally important protein interacting domains, than a classical gene knockout. This may be particularly applicable to the pharmaceutical industry, because typically the mode of action of drugs is to alter the activity of proteins rather than eliminate their function, or to target specific residues of an active site, for example (Russ et al. 2002). Alternatively, a knockin of the desired mutation might provide a suitable genetic model; however, the time and cost constraints of generating one or more mutant lines using this method is often prohibitive. An engineered mutant trangene might provide a more rapid solution, although studies of transgenic lines are often confounded by factors such as epitope tags, multiple insertions, incorrect promoter artifacts, or position effects that do not influence ENU point mutations that have the advantage of always occurring at the endogneous genomic position. Consequently, an ENU mutation that is not known to be causative in human disease is still likely to provide valuable insights into gene function.

However, the practicalities of large-scale phenotypedriven mouse mutagenesis, such as the limitation and bias of the phenotyping methods, means that many potentially interesting or subtle phenotypes may simply not be detected in a first-pass screen; consequently, mutagenesis centers routinely cryopreserve tissues from each new mutant line for future rederivation and genotyping regardless of the phenotypic data obtained (Glenister and Thornton 2000). These resources, in combination with recent advances in the rapid detection of mutations by denaturing high-performance liquid chromatography (DHPLC) (Dobson-Stone et al. 2000) and temperature gradient capillary electrophoresis (TGCE) (Culiat et al. 2005; Sakuraba et al. 2005), have made it practical to use a gene-driven approach to mouse mutant detection. Here, a gene of interest can be efficiently screened for mutations by PCR from thousands of individual DNA samples followed by rederivation of the selected lines for further study (Coghill et al. 2002; Michaud et al. 2005). This technique is also applicable to ES cells that are amenable to random chemical mutagenesis and PCR screening (Chen et al. 2000; Munroe et al. 2004). Although there is no guarantee of any measureable phenotype in the resulting mutant, it has been calculated from pilot studies that 5000 DNA samples is sufficient to identify at least two alleles with $90 \%$ confidence (Coghill et al. 2002; Quwailid et al. 2004). Such values are based on estimating the proportion of the genome that is protein coding; therefore, assuming no positional bias in the mutagenic action of ENU, the larger the gene, the greater the likelihood of identifying a new mutation (Concepcion et al. 2004). With the size of these archives increasing and other academic centers such as RIKEN generating similar resources (Sakuraba et al. 2005), gene-driven screening will play an increasingly important role in the identification of multiple mutant alleles. Another, sometimes overlooked, advantage of such strategies is that all the resulting mutants from a particular ENU screen will be derived from the same genetic background, a vital feature for comparative assessment. It is well known that inbred lines differ considerably in a large number of physiologic and behavioral parameters (Contet et al. 2001; Kaku et al. 1988; Solberg et al. 2006), which may confound attempts to accurately compare spontaneous mutant or knockout lines on different backgrounds (Lalouette et al. 1998; Runkel et al. 2004).

\section{Allelic series in mouse: genotype-phenotype correlations}

Historically, the first large collections of allelic series were derived from early genetic studies that analyzed the offspring of mutagenized male mice with females homozygous for a mutation that causes a visible phenotype such as coat color. These specific locus tests were not only used to titrate the effectiveness of particular mutagens accurately, but they also generated dozens of alleles at these particular loci, such as dilute and short-ear (Davis and Justice 1998a, 1998b). There are also numerous examples of allelic spontaneous mutants, although these are, as expected, biased toward visible phenotypes such as gait dysfunction (Lalouette et al. 1998; Letts et al. 2003). There is now an increasing number of mutiple mutant alleles representing individual genes; a range of the more recent examples that 
have used large-scale mutagenesis are outlined in Table 1. Although not an exhausative list, some of those that have highlighted the various experimental features of this method and have provided the most interesting functional insights are decribed below.

\section{Pmp22: insights into human peripheral neuropathies}

The random nature of ENU as a mutagen provides a sound basis for the discovery of novel disease models; however, in a phenotype-driven screen there will naturally be a bias toward those defects that are early onset, easy to recognize, and nonlethal. Some of the earliest examples of an allelic series identified from a large-scale ENU screen are the three Trembler mutants $\operatorname{Tr}^{m 1 H}, \operatorname{Tr}^{m 2 H}$, and $T r^{m 3 H}$. These dominant mutants displayed a range of resting tremor and hind-limb grasping behavior, with $T r^{m 1 H}$ the most severely affected and $\operatorname{Tr}^{m 3 H}$ the least (Isaacs et al. 2000, 2002). Quantitative histopathologic analysis revealed that there was a direct correlation between the severity of the phenotype and the level of hypomyelination in the peripheral nerve of the mutant mice; $\operatorname{Tr}^{m I H}$ displayed the fewest and most narrowed axonal profiles and the greatest increase in endoneurial connective tissue of all the lines. The causative mutations were identified in peripheral myelin protein 22 (Pmp22), a highly conserved structural component of the axonal myelin sheath already implicated in peripheral neuropathies in humans (Isaacs et al. 2000, 2002). The $\mathrm{Tr}^{\mathrm{mlH}}$ mutation (H12R) is in an identical position as an amino acid substitution described in a patient suffering from Derjerine-Sottas syndrome (DSS), a severe demylelinating neuropathy (Valentijn et al. 1995). In addition, the Ser72 altered in the relatively mild $T^{m 3 H}$ line is a putative hotspot for PMP22 mutations that relate to the same disorder (Marques et al. 1998, 2004). This serine-to-threonine change is far more conservative than the four human mutations documented at the same residue in DSS patients, suggesting a strong association between genotype and phenotype. Interestingly, this can also be applied to two spontaneous Pmp22 mutants; the Pmp22-Tr mutation causes a severe tremor in mice and occurs in another conserved position altered in DSS patients (Ionasescu et al. 1997; Suter et al. 1992), whereas the less severe CharcotMarie-Tooth disease type 1A (CMT1A) can be caused by identical mutations found in the milder Tr-J mutant (Valentijn et al. 1992). The Pmp22 knockout also displays resting tremor and hypomyelination, although the phenotype is less severe than $\operatorname{Tr}$ or $T r^{m l H}$, suggesting that the disease progression is not simply due to a loss-of-function effect (Adlkofer et al. 1995). Indeed, in vitro modeling experiments proposed that expression of mutant Pmp22 caused retention of wild-type protein away from the membrane (Colby et al. 2000). Importantly, similar experiments with the three ENU lines showed there was a direct relationship between the severity of the phenotype and the propensity of Pmp22 to form oligomers in vitro (Isaacs et al. 2002). The allelic series of Pmp22 mutants has therefore provided valuable insight into the genotypephenotype correlation of peripheral neuropathies in humans.

$G k$ : modeling multiple human mutations in new diabetes models

Inactivating mutations in glucokinase (GK), a critical glycolysis enzyme and "glucose sensor" in insulin secreting $\beta$ cells, are known to cause dominant maturityonset diabetes of the young type 2 (MODY2) and recessive permanent neonatal diabetes mellitus (PNDM) (Njolstad et al. 2001; Vionnet et al. 1992). Mouse $G k$ knockout models have provided some insight into disease-causing mechanisms, although they have not revealed details of the structure-function relationships of this important metabolic protein (Postic et al. 1999). Moreover, over 190 missense, nonsense, and splicing mutations in GK have been described in MODY2 alone, suggesting that similar genetic lesions in mice would provide the most clinically relevant information (Gloyn 2003). Two independent groups have combined large-scale ENU mutagenesis with a biochemical screening approach to identify new mouse models of diabetes and have identified a total of $12 \mathrm{Gk}$ mutations with distinct enzyme properties and hyperglycemic phenotypes (Inoue et al. 2004; Toye et al. 2004). For example, Inoue et al. demonstrated that three of their missense mutations (M-272, M-341, and M-392) caused a marked reduction in GK activity, hyperglycemia, and glucose intolerance, although only two of these (M-272 and M-341) showed a corresponding reduction in protein level, suggesting that $G k$ mutations can cause protein instabilty in addition to directly affecting the function of the enzyme (M-392). Another point mutation (M-210) occurred at the splice donor site of the $\beta$-cell-specific exon 1 , causing a similar hyperglycemic phenotype and confirming that disruption of this isoform is sufficient to impair glucose regulation as observed in $\beta$-cell-specific $G k$ knockout mice (Postic et al. 1999). This allelic series also demonstrated that the degree of severity is significantly influenced by the position of the $G k$ mutation if homozygous. Severe hyperglycemia in M210 homozygous mutant pups was first detectable at postnatal day $2(\mathrm{P} 2)$, in addition to marked growth retardation, liver abnormalities, and eventual death by P7. By contrast, the M-392 point mutation produced a milder hyperglycemic phenotype when homozygous, with no overt growth retardation or liver defects (Inoue et al. 2004). The differing phenotypes are related to the relative position of the mutations; M-210 homozygous mice have a phe- 
notype similar to $G k$ knockouts, whereas the M-392 mutation occurs in the glucose-binding region as opposed to the more functionally significant catalytic domain (GidhJain et al. 1993). Importantly, four of the newly identified $G k$ mutations, including the $\beta$-cell-specific substiution, are identical to those found in humans (Gloyn 2003); the missense mutation (M-236) at Thr288 is not only identical to mutations found in both MODY2 and PNDM patients, but it is situated in the active site of GK, correlating directly with the reported significant reduction in kinase activity of the enzyme (Davis et al. 1999; Gidh-Jain et al. 1993). These new mutants have provided a detailed structure-function study of GK and the relationship between varying levels of its inactivation to hyperglycemic phenotypes that are directly relevant to both dominant and recessive forms of diabetes.

\section{Quaking: functional analysis of protein isoforms}

The RNA binding protein encoded by the quaking loci mediates the stabilty and splicing of oligodendrocyte RNA transcripts such as myelin basic protein (MBP) and exists in three distinct isforms: QKI-5, -6, and -7 (Wu et al. 2002). A total of five ENU-induced mutants have since been identified by their failure to complement the original spontaneous $q k^{v} / q k^{v}$ line: four that are homozygous embryonic lethal $\left(q k^{k t 1 m}, q k^{k 2}, q k^{k t 3 / 4}\right.$, and $\left.q k^{l-1}\right)$ and a single viable allele $\left(q k^{e 5}\right)$ that causes seizures in the second postnatal week in addition to adult-onset progressive ataxia (Justice and Bode 1988; Noveroske et al. 2005). In addition to demonstrating an unexpected developmental role for this gene, subtle yet significant differences in the embryonic phenotypes of the four lethal lines have revealed new information regarding the functional domains of the QKI isoforms. For example, the $q k^{k 2}$ mutation causes death at embryonic day (E) 8.5-11.5 due to a disorganization of the anterior-posterior (A-P) axis, in addition to cranial and heart defects (Justice and Bode 1988). The causative mutation appears to be inherited in a semidominant manner and occurs at a highly conserved amino acid in the RNAbinding $(\mathrm{KH})$ domain common to all three QKI isoforms (Cox et al. 1999). In contrast, a splice site is disrupted in the recessive $q k^{l-1}$ mutant, leading to a loss of the QKI-5 protein and cessation of development between E8.0 and E9.0, suggesting that disruption of the nuclear isoform is sufficient to cause embryonic lethality (Cox et al. 1999; Justice and Bode 1988). Despite the viability of $q k^{e 5} / q k^{e 5}$ mice, severe dysmyelination of the brain is evident, in addition to the presence of axonal swellings in the cerebellum that are likely to account for the observed ataxia. Expression studies revealed that the QKI-6 and -7 isoforms are not present in mutant postnatal oligodendrocytes and levels of QKI-5 are considerably reduced, although all three isoforms appear to be expressed at normal levels in astrocytes (Noveroske et al. 2005). Because no coding mutations in the quaking loci were identified, this evidence points to disruption of an as-yet unidentified tissue-specific regulatory region. Further examination showed that markers of mature oligodendrocytes were disrupted in $q k^{e 5} / q k^{e 5}$ mice, suggesting that the severe phenotype is due to defective myelination by QKI-regulated pathways rather than to aberant development of these cells during proliferation. The biological importance of the $q k^{e 5}$ mutant is also emphasized by the fact that the original viable $q k^{v}$ line contains a large deletion that disrupts two additional genes that are likely to influence the demyelination phenotype (Lorenzetti et al. 2004). This ENU-derived allelic series has not only revealed a new role for quaking in embryonic vasculogenesis, but it has also demonstrated that regulation of the gene is critical for normal CNS myelination; these mutants are a useful resource for modeling seizure and neural tube defects in addition to psychiatric disorders such as schizophrenia to which human QKI has recently been associated (Haroutunian et al. 2006).

Pde6b: new models of retinal degeneration

From a phenotype-driven screen of over 6000 ENU mutants for vision defects detectable by either microscopy or visual tracking response, 25 inherited phenotypes were isolated, with 7 of these caused by mutations in Pde6b, a gene previously implicated in eye pathophysiology (Thaung et al. 2002). Mutations in the $\beta$ subunit of the rod cGMP-phosphodiesterase (PDE6B) gene have been shown to account for approximately $2 \%$ of cases of retinitis pigmentosa (RP), causing degeneration of the retina and blindness (McLaughlin et al. 1995). Mice homozygous for the null Pde6b allele $\left(P d e 6 b^{r d l}\right)$ provide a model for autosomal recessive (ar) RP, but suffer from almost complete photoreceptor apoptotic degeneration by three weeks of age due to persistent opening of cGMP-gated cation channels (Chang et al. 1993). Consequently, a Pde6b allelic series containing mutants with slower disease onset would be more practical as a tool for analyzing potential therapeutic strategies. Four of the novel recessive mutants identified $\left(P d e 6 b^{r d 1-1-4 H}\right)$ displayed essentially identical phenotypes to the endogenous $P d e 6 b^{r d 1}$ alleles of the $\mathrm{C} 3 \mathrm{H}$ mouse strain; however, the remaining lines showed varying degrees of post-weaning-onset atypical retinal degeneration (atrd), named Pde6b ${ }^{\text {atrd1-3 }}$ (Hart et al. 2005; Thaung et al. 2002). As expected from their related pathology to $P d e 6 b^{r d l}$ mice, the four $P d e 6 b^{1-4 H}$ mutants contained mutations that are predicted to cause loss of function: three generated premature stop codons and the fourth altered a highly conserved splice donor site. Interestingly, the latter mutation is identical to one found in a patient with arRP, 
once again correlating ENU mutants with aberant human alleles (McLaughlin et al. 1995). Of the three less severe alleles, two mutations ( $P d e 6 b^{a t r d 1}$ and $\left.P d e 6 b^{a t r d 3}\right)$ were in the catalytic domain of Pde6b and the third $\left(P d e 6 b^{a t r d 2}\right)$ occurred in another splice donor site. Molecular analysis of $P d e 6 b^{\text {atrd } 2}$ transcripts showed that the predominant product was truncated and presumably nonfunctional, although $17 \%$ of the transcripts analyzed were correctly spliced and expressed, presumably accounting for the milder retinal degeneration seen in this mutant line compared to $r d l$ mice (Hart et al. 2005). Combined visual acuity, fundus, and histopathologic analysis of the three atrd lines showed that Pde $6 b^{\text {atrd1 }}$ displays the least severe phenotype; this may reflect the fact that in related phosphodiesterases the mutated histidine is replaced by a tyrosine, indicating that this residue is not necessarily functionally essential. By contrast, the asparagine mutated in Pde6b $b^{\text {atrd3 }}$ mice is conserved in all known mammalian phosphodiesterases, and this is reflected in a reduced visual acuity performance compared with those homozygous for the Pde6b ${ }^{\text {atrdl }}$ allele (Hart et al. 2005). The strong genotype-phenotype correlation in this study has shed new light on the functional domains of Pde6b as well as provide valuable new models for RP and related disorders.

\section{Smad4: ES cell-derived gene-driven screening}

Whereas gene-driven screens from whole-animal archives have proved to be successful, the initial cost and space involved in generating thousands of lines may be prohibitive (Williams et al. 2003). Consequently, a number of groups have established mutagenized ES cell libraries for PCR screening and subsequent recovery (Chen et al. 2000; Munroe et al. 2004). The validity of this approach has been demonstrated by the identification of 29 Smad2 and Smad4 mutations in a screen of over 2000 ENU-mutagenized ES cell clones (Vivian et al. 2002). Both genes, transducers of transforming growth factor $\beta$ (TGF- $\beta$ ) superfamily signaling, have been implicated in the development of human cancers (Miyaki and Kuroki 2003), although the perigastrulation lethality of knockouts has limited research into their role in late embryonic stages or adult life (Weinstein et al. 2000). A series of Smad4 mutants was recovered and, unexpectedly, three of these lines, Smad ${ }^{m 1 M a g}, \operatorname{Smad}^{\text {m2Mag, }}$, and Smad ${ }^{\text {mMag }}$, were viable in the homozygous state and displayed no detectable phenotype in adults despite missense substitutions in three conserved residues spread throughout the protein. The Smad4 $4^{\text {4Mag }}$ mutation, however, occurred in a splice donor site, causing the deletion of an exon and the generation of a truncated protein with 19 additional out-of-frame amino acids. Homozygous Smad4 ${ }^{\text {4Mag }}$ mutants, unsurprisingly, did not survive embryogenesis and failed to initiate gastrulation. Interest- ingly, ES cells heterozygous for the mutation showed steady-state Smad4 protein levels considerably lower than expected, suggesting that the mutant protein may confer instability to wild-type Smad4 (Vivian et al. 2002). This was confirmed by further biochemical analysis that demonstrated that the truncated protein is not only targeted for proteosomal degradation but can form a complex with wild-type Smad4, targeting it for proteolysis (Chen et al. 2006). This pilot study illustrates that although an ES-cell gene-driven approach can be used to generate allelic series, because of the random nature of the mutagen not all new lines may have a functional effect on the gene of interest.

The MFCS1 element: mutation analysis of a regulatory region

While the vast majority of gene-driven screens have concentrated on exonic and splice site regions, the method can equally be applied to any genomic sequence. A recent study has screened a short, well-characterized cis-acting element, Mammal-fish-conserved-sequence 1 (MFCS1), which regulates the expression of the polarity-signaling protein Sonic hedgehog (Shh) (Masuya et al. 2007). In humans there are a number of cases of preaxial polydactyly (PPD) caused by point mutations in MFCS1 (Lettice et al. 2003; Maas and Fallon 2005); however, no molecular motifs have been discovered in this region that explain the mechanisms involved in $S h h$ regulation by an element situated over $1 \mathrm{Mb}$ upstream of the coding region (Lettice et al. 2002). From over 3500 mutant mice screened, three new mutations were discovered, M101116, M101117, and M101192, flanking the pre-existing PPD ENU mutant M100081 (Sagai et al. 2004). M101117 and M101192 showed no limb dismorphology, whereas the remaining lines had a semidominant PPD phenotype, with M100081 also showing tibial hemimelia when in the homozygous state. Ectopic expression of Shh was detected in the anterior region of the hind-limb bud of M100081 and M101116 homozygotes at E10.5, which was confirmed by transgenic analysis of embryos generated with the $L a c Z$ reporter gene under the control of mutated MFCS1. As expected, the level of ectopic Shh expression correlated with the relative severity of the PDD phenotype, but also with the evolutionary conservation of the mutated nucleotide; the M100081 and M101116 substitutions occur at positions found in fugu, whereas the nucleotide positions altered in the less severe M10117 and M101192 lines are conserved only as far as chicken. The molecular mechanisms controlling these observations remain unclear and may relate to aberrant binding of transcription factors. However, this study highlights the power of this strategy to identify novel features of regulatory elements, a natural progression from the current mutation analysis of protein-coding domains. 


\section{Conclusions and future prospects}

The cost of generating a new allelic series is continually decreasing with advances in DNA analysis and the expansion of mutant mouse archives. For example, combining TGCE with over 17,000 mutant genomic DNA samples, Ingenium Pharmaceuticals state they are able to generate at least five new alleles for any given gene and provide live adult mutant mice within three to four months (Augustin et al. 2005). With this number of novel strains available, preselection of the most biologically relevant mutations will become routine and necessary in many cases (Grosse et al. 2006). Improvements in ES cell technology have also enhanced the efficiency of gene-driven screens from mutagenized stem cell archives. Recovery of these lines has traditionally relied on introducing ES cells into blastocycts, followed by two rounds of breeding to generate mice homozygous for the desired mutation. Hybrid ES cell lines and tetraploid host embryos can facilitate the identification of phenotypes in the first generation $\left(\mathrm{F}_{0}\right)$, although this method suffers from a number of confounding technical inefficiencies that preclude its use as a highthroughput strategy. The latest advance uses laser-assisted injection of ES cells into eight-cell-stage embryos, generating viable $\mathrm{F}_{0}$ mice of both sexes that are nearly $100 \%$ chimeric. A pilot study demonstrated that the phenotype of previously characterized mutations could be successfully recapitulated in mice recovered from ES cells using this method (Poueymirou et al. 2007). It has even been possible to identify and successfully rederive new splice variants from a highly pooled archive of 40,000 mutagenized ES cell clones using nested exon-skipping PCR primers (Greber et al. 2005). Because the time and cost of these high-thoughput technologies is decreasing, the availability of an "off-the-shelf"' series of mutations for a given gene is slowly becoming a reality.

It must not be overlooked, however, that each new ENU mutant line harbors many other mutations in addition to the one that may have been identified by gene-driven screening (Hitotsumachi et al. 1985). The estimate that one functional animo acid change is obtained every $1.82 \mathrm{Mb}$ of coding DNA was determined from a gene-based screen of the Harwell ENU archive (Quwailid et al. 2004). Consequently it was calculated that there is still a $7 \%$ chance that a second confounding mutation is linked to the originally identified loci after ten generations of backcrossing to a wild-type strain (Keays et al. 2006). Marker-assisted selection (MAS), in which offspring with the smallest amount of donor chromosome linked to the mutation of interest are used for breeding, can be used to circumvent this problem (Visscher et al. 1996). Although this may detract from the apparent speed and convenience of a genedriven approach, additional experimental evidence such as a BAC rescue (Keays et al. 2007) or even a second allelic mutation (Hafezparast et al. 2003) can provide sufficient supporting evidence that a novel genetic lesion is causative.

As the studies above have illustrated, multiple-mutant alleles frequently provide valuable insight into gene function, including unexpected and serendipitous findings, as a consequence of the random nature of ENU mutagenesis. The power of this technique relies on evolutionary conservation of DNA sequence and physiologic parameters to extrapolate conclusions to human disease states; consequently, the mouse will continue to provide important and clinically relevant phenotypes. Moreover, there is likely to be a move toward mutation screening of non-protein-coding regions such as promoter elements, introns, and noncoding RNAs as more is learned about their role in biology. For example, the modeling of human point mutations in the noncoding RMRP RNA has provided new insight into the role of this component of the ribonucleoprotein complex in cartilage-hair hypoplasia (Hermanns et al. 2005). There is no doubt, therefore, that large-scale chemical mutagenesis, in combination with other genetic tools such as conventional and conditional knockouts, knockins, and transgenics will continue to play a vital role in the generation of new therapeutic targets.

\section{References}

Adlkofer K, Martini R, Aguzzi A, Zielasek J, Toyka KV, et al. (1995) Hypermyelination and demyelinating peripheral neuropathy in Pmp22-deficient mice. Nat Genet 11:274-280

Antonarakis SE, Beckmann JS (2006) Mendelian disorders deserve more attention. Nat Rev Genet 7:277-282

Augustin M, Sedlmeier R, Peters T, Huffstadt U, Kochmann E, et al. (2005) Efficient and fast targeted production of murine models based on ENU mutagenesis. Mamm Genome 16:405-413

Austin CP, Battey JF, Bradley A, Bucan M, Capecchi M, et al. (2004) The knockout mouse project. Nat Genet 36:921-924

Bitoun E, Davies KE (2005) The robotic mouse: unravelling the function of AF4 in the cerebellum. Cerebellum 4:1-11

Bitoun E, Oliver PL, Davies KE (2007) The mixed-lineage leukemia fusion partner AF4 stimulates RNA polymerase II transcriptional elongation and mediates coordinated chromatin remodeling. Hum Mol Genet 16:92-106

Bosman EA, Penn AC, Ambrose JC, Kettleborough R, Stemple DL, et al. (2005) Multiple mutations in mouse Chd7 provide models for CHARGE syndrome. Hum Mol Genet 14:3463-3476

Branda CS, Dymecki SM (2004) Talking about a revolution: The impact of site-specific recombinases on genetic analyses in mice. Dev Cell 6:7-28

Brown SD, Balling R (2001) Systematic approaches to mouse mutagenesis. Curr Opin Genet Dev 11:268-273

Brown SD, Peters J (1996) Combining mutagenesis and genomics in the mouse-closing the phenotype gap. Trends Genet 12:433-435

Buchner DA, Seburn KL, Frankel WN, Meisler MH (2004) Three ENU-induced neurological mutations in the pore loop of sodium channel Scn8a $(\mathrm{Na}(\mathrm{v}) 1.6)$ and a genetically linked retinal mutation, rd13. Mamm Genome 15:344-351 
Chang GQ, Hao Y, Wong F (1993) Apoptosis: final common pathway of photoreceptor death in rd, rds, and rhodopsin mutant mice. Neuron 11:595-605

Chen WV, Soriano P (2003) Gene trap mutagenesis in embryonic stem cells. Methods Enzymol 365:367-386

Chen Y, Yee D, Dains K, Chatterjee A, Cavalcoli J, et al. (2000) Genotype-based screen for ENU-induced mutations in mouse embryonic stem cells. Nat Genet 24:314-317

Chen Y, Yee D, Magnuson T (2006) A novel mouse Smad4 mutation reduces protein stability and wild-type protein levels. Mamm Genome 17:211-219

Cobellis G, Nicolaus G, Iovino M, Romito A, Marra E, et al. (2005) Tagging genes with cassette-exchange sites. Nucleic Acids Res 33:e44

Coghill EL, Hugill A, Parkinson N, Davison C, Glenister P, et al. (2002) A gene-driven approach to the identification of ENU mutants in the mouse. Nat Genet 30:255-256

Colby J, Nicholson R, Dickson KM, Orfali W, Naef R, et al. (2000) PMP22 carrying the trembler or trembler-J mutation is intracellularly retained in myelinating Schwann cells. Neurobiol Dis 7:561-573

Concepcion D, Seburn KL, Wen G, Frankel WN, Hamilton BA (2004) Mutation rate and predicted phenotypic target sizes in ethylnitrosourea-treated mice. Genetics 168:953-959

Contet C, Rawlins JN, Deacon RM (2001) A comparison of 129S2/ SvHsd and C57BL/6JOlaHsd mice on a test battery assessing sensorimotor, affective and cognitive behaviours: implications for the study of genetically modified mice. Behav Brain Res 124:33-46

Cordes SP (2005) N-ethyl-N-nitrosourea mutagenesis: boarding the mouse mutant express. Microbiol Mol Biol Rev 69:426-439

Cox RD, Hugill A, Shedlovsky A, Noveroske JK, Best S, et al. (1999) Contrasting effects of ENU induced embryonic lethal mutations of the quaking gene. Genomics 57:333-341

Culiat CT, Klebig ML, Liu Z, Monroe H, Stanford B, et al. (2005) Identification of mutations from phenotype-driven ENU mutagenesis in mouse chromosome 7. Mamm Genome 16:555-566

Davis AP, Justice MJ (1998a) Mouse alleles: if you've seen one, you haven't seen them all. Trends Genet 14:438-441

Davis AP, Justice MJ (1998b) An Oak Ridge legacy: the specific locus test and its role in mouse mutagenesis. Genetics 148:7-12

Davis EA, Cuesta-Munoz A, Raoul M, Buettger C, Sweet I, et al. (1999) Mutants of glucokinase cause hypoglycaemia and hyperglycaemia syndromes and their analysis illuminates fundamental quantitative concepts of glucose homeostasis. Diabetologia 42:1175-1186

Dobson-Stone C, Cox RD, Lonie L, Southam L, Fraser M, et al. (2000) Comparison of fluorescent single-strand conformation polymorphism analysis and denaturing high-performance liquid chromatography for detection of EXT1 and EXT2 mutations in hereditary multiple exostoses. Eur J Hum Genet 8:24-32

Elsea SH, Lucas RE (2002) The mousetrap: what we can learn when the mouse model does not mimic the human disease. ILAR J 43:66-79

Favor J (1983) A comparison of the dominant cataract and recessive specific-locus mutation rates induced by treatment of male mice with ethylnitrosourea. Mutat Res 110:367-382

Favor J (1986) The frequency of dominant cataract and recessive specific-locus mutations in mice derived from 80 or $160 \mathrm{mg}$ ethylnitrosourea per $\mathrm{kg}$ body weight treated spermatogonia. Mutat Res 162:69-80

Favor J, Neuhauser-Klaus A (2000) Saturation mutagenesis for dominant eye morphological defects in the mouse Mus musculus. Mamm Genome 11:520-525

Favor J, Peters H, Hermann T, Schmahl W, Chatterjee B, et al. (2001) Molecular characterization of Pax6(2Neu) through Pax6(10-
Neu): an extension of the Pax6 allelic series and the identification of two possible hypomorph alleles in the mouse Mus musculus. Genetics 159:1689-1700

Favor J, Gloeckner CJ, Janik D, Klempt M, Neuhauser-Klaus A, et al. (2007) Type IV procollagen missense mutations associated with defects of the eye, vascular stability, brain, kidney function and embryonic or postnatal viability in the mouse, Mus musculus: An extension of the Col4a1 allelic series and the identification of the first 2 Col4a2 mutant alleles. Genetics 175:725-736

Garry DJ, Ordway GA, Lorenz JN, Radford NB, Chin ER, et al. (1998) Mice without myoglobin. Nature 395:905-908

Ghebranious N, Donehower LA (1998) Mouse models in tumor suppression. Oncogene 17:3385-3400

Gidh-Jain M, Takeda J, Xu LZ, Lange AJ, Vionnet N, et al. (1993) Glucokinase mutations associated with non-insulin-dependent (type 2) diabetes mellitus have decreased enzymatic activity: implications for structure/function relationships. Proc Natl Acad Sci U S A 90:1932-1936

Gingrich JA, Hen R (2000) The broken mouse: the role of development, plasticity and environment in the interpretation of phenotypic changes in knockout mice. Curr Opin Neurobiol 10:146-152

Glenister PH, Thornton CE (2000) Cryoconservation-archiving for the future. Mamm Genome 11:565-571

Gloyn AL (2003) Glucokinase (GCK) mutations in hyper- and hypoglycemia: maturity-onset diabetes of the young, permanent neonatal diabetes, and hyperinsulinemia of infancy. Hum Mutat 22:353-362

Graw J, Klopp N, Loster J, Soewarto D, Fuchs H, et al. (2001) Ethylnitrosourea-induced mutation in mice leads to the expression of a novel protein in the eye and to dominant cataracts. Genetics 157:1313-1320

Graw J, Neuhauser-Klaus A, Loster J, Klopp N, Favor J (2002) Ethylnitrosourea-induced base pair substitution affects splicing of the mouse gammaE-crystallin encoding gene leading to the expression of a hybrid protein and to a cataract. Genetics $161: 1633-1640$

Graw J, Neuhauser-Klaus A, Klopp N, Selby PB, Loster J, et al. (2004) Genetic and allelic heterogeneity of Cryg mutations in eight distinct forms of dominant cataract in the mouse. Invest Ophthalmol Vis Sci 45:1202-1213

Graw J, Loster J, Puk O, Munster D, Haubst N, et al. (2005) Three novel Pax6 alleles in the mouse leading to the same small-eye phenotype caused by different consequences at target promoters. Invest Ophthalmol Vis Sci 46:4671-4683

Greber B, Lehrach H, Himmelbauer H (2005) Mouse splice mutant generation from ENU-treated ES cells-a gene-driven approach. Genomics 85:557-562

Grosse J, Tarnow P, Rompler H, Schneider B, Sedlmeier R, et al. (2006) N-ethyl-N-nitrosourea-based generation of mouse models for mutant $G$ protein-coupled receptors. Physiol Genomics 26:209-217

Hafezparast M, Klocke R, Ruhrberg C, Marquardt A, Ahmad-Annuar A, et al. (2003) Mutations in dynein link motor neuron degeneration to defects in retrograde transport. Science 300:808-812

Hakem R, Mak TW (2001) Animal models of tumor-suppressor genes. Annu Rev Genet 35:209-241

Hamosh A, Scott AF, Amberger JS, Bocchini CA, McKusick VA (2005) Online Mendelian Inheritance in Man (OMIM), a knowledgebase of human genes and genetic disorders. Nucleic Acids Res 33:D514-D517

Haroutunian V, Katsel P, Dracheva S, Davis KL (2006) The human homolog of the QKI gene affected in the severe dysmyelination "quaking" mouse phenotype: downregulated in multiple brain regions in schizophrenia. Am J Psychiatry 163:1834-1837 
Hart AW, McKie L, Morgan JE, Gautier P, West K, et al. (2005) Genotype-phenotype correlation of mouse pde6b mutations. Invest Ophthalmol Vis Sci 46:3443-3450

Hermanns P, Bertuch AA, Bertin TK, Dawson B, Schmitt ME, et al. (2005) Consequences of mutations in the non-coding RMRP RNA in cartilage-hair hypoplasia. Hum Mol Genet 14:37233740

Hitotsumachi S, Carpenter DA, Russell WL (1985) Dose-repetition increases the mutagenic effectiveness of N-ethyl-N-nitrosourea in mouse spermatogonia. Proc Natl Acad Sci U S A 82:66196621

Hochgeschwender U, Brennan MB (1995) Mouse knockouts rule OK. Nature 375:543

Hrabe de Angelis M, Balling R (1998) Large scale ENU screens in the mouse: genetics meets genomics. Mutat Res 400:25-32

Hrabe de Angelis MH, Flaswinkel H, Fuchs H, Rathkolb B, Soewarto D, et al. (2000) Genome-wide, large-scale production of mutant mice by ENU mutagenesis. Nat Genet 25:444-447

Huang JD, Mermall V, Strobel MC, Russell LB, Mooseker MS, et al. (1998a) Molecular genetic dissection of mouse unconventional myosin-VA: tail region mutations. Genetics 148:1963-1972

Huang JD, Cope MJ, Mermall V, Strobel MC, Kendrick-Jones J, et al. (1998b) Molecular genetic dissection of mouse unconventional myosin-VA: head region mutations. Genetics 148:1951-1961

Im WB, Phelps SF, Copen EH, Adams EG, Slightom JL, et al. (1996) Differential expression of dystrophin isoforms in strains of $\mathrm{mdx}$ mice with different mutations. Hum Mol Genet 5:1149-1153

Inoue M, Sakuraba Y, Motegi H, Kubota N, Toki H, et al. (2004) A series of maturity onset diabetes of the young, type 2 (MODY2) mouse models generated by a large-scale ENU mutagenesis program. Hum Mol Genet 13:1147-1157

Ionasescu VV, Searby CC, Ionasescu R, Chatkupt S, Patel N, et al. (1997) Dejerine-Sottas neuropathy in mother and son with same point mutation of PMP22 gene. Muscle Nerve 20:97-99

Isaacs AM, Davies KE, Hunter AJ, Nolan PM, Vizor L, et al. (2000) Identification of two new Pmp22 mouse mutants using largescale mutagenesis and a novel rapid mapping strategy. Hum Mol Genet 9:1865-1871

Isaacs AM, Jeans A, Oliver PL, Vizor L, Brown SD, et al. (2002) Identification of a new Pmp22 mouse mutant and trafficking analysis of a Pmp22 allelic series suggesting that protein aggregates may be protective in Pmp22-associated peripheral neuropathy. Mol Cell Neurosci 21:114-125

Isaacs AM, Oliver PL, Jones EL, Jeans A, Potter A, et al. (2003) A mutation in Af4 is predicted to cause cerebellar ataxia and cataracts in the robotic mouse. J Neurosci 23:1631-1637

Isnard P, Core N, Naquet P, Djabali M (2000) Altered lymphoid development in mice deficient for the mAF4 proto-oncogene. Blood 96:705-710

Justice MJ (2000) Capitalizing on large-scale mouse mutagenesis screens. Nat Rev Genet 1:109-115

Justice MJ, Bode VC (1988) Three ENU-induced alleles of the murine quaking locus are recessive embryonic lethal mutations. Genet Res 51:95-102

Kaku K, Fiedorek FT Jr, Province M, Permutt MA (1988) Genetic analysis of glucose tolerance in inbred mouse strains. Evidence for polygenic control. Diabetes 37:707-713

Keays DA, Nolan PM (2003) N-ethyl-N-nitrosourea mouse mutants in the dissection of behavioural and psychiatric disorders. Eur J Pharmacol 480:205-217

Keays DA, Clark TG, Flint J (2006) Estimating the number of coding mutations in genotypic- and phenotypic-driven N-ethyl-N-nitrosourea (ENU) screens. Mamm Genome 17:230-238

Keays DA, Tian G, Poirier K, Huang GJ, Siebold C, et al. (2007) Mutations in alpha-tubulin cause abnormal neuronal migration in mice and lissencephaly in humans. Cell 128:45-57
Kiernan AE, Erven A, Voegeling S, Peters J, Nolan P, et al. (2002) ENU mutagenesis reveals a highly mutable locus on mouse Chromosome 4 that affects ear morphogenesis. Mamm Genome 13:142-148

Kono M, Mi Y, Liu Y, Sasaki T, Allende ML, et al. (2004) The sphingosine-1-phosphate receptors S1P1, S1P2, and S1P3 function coordinately during embryonic angiogenesis. J Biol Chem 279:29367-29373

Kuznetsov VV (2003) RNA interference. An approach to produce knockout organisms and cell lines. Biochemistry (Mosc) 68:1063-1076

Lalouette A, Guenet JL, Vriz S (1998) Hotfoot mouse mutations affect the delta 2 glutamate receptor gene and are allelic to lurcher. Genomics 50:9-13

LeRoith D, Gavrilova O (2006) Mouse models created to study the pathophysiology of Type 2 diabetes. Int $\mathrm{J}$ Biochem Cell Biol 38:904-912

Lettice LA, Horikoshi T, Heaney SJ, van Baren MJ, van der Linde HC, et al. (2002) Disruption of a long-range cis-acting regulator for Shh causes preaxial polydactyly. Proc Natl Acad Sci U S A 99:7548-7553

Lettice LA, Heaney SJ, Purdie LA, Li L, de Beer P, et al. (2003) A long-range Shh enhancer regulates expression in the developing limb and fin and is associated with preaxial polydactyly. Hum Mol Genet 12:1725-1735

Letts VA, Kang MG, Mahaffey CL, Beyer B, Tenbrink H, et al. (2003) Phenotypic heterogeneity in the stargazin allelic series. Mamm Genome 14:506-513

Lorenzetti D, Bishop CE, Justice MJ (2004) Deletion of the Parkin coregulated gene causes male sterility in the quaking(viable) mouse mutant. Proc Natl Acad Sci U S A 101:8402-8407

Maas SA, Fallon JF (2005) Single base pair change in the long-range Sonic hedgehog limb-specific enhancer is a genetic basis for preaxial polydactyly. Dev Dyn 232:345-348

Marker PC, Seung K, Bland AE, Russell LB, Kingsley DM (1997) Spectrum of Bmp5 mutations from germline mutagenesis experiments in mice. Genetics 145:435-443

Marques W Jr, Thomas PK, Sweeney MG, Carr L, Wood NW (1998) Dejerine-Sottas neuropathy and PMP22 point mutations: a new base pair substitution and a possible "hot spot" on Ser72. Ann Neurol 43:680-683

Marques W Jr, Neto JM, Barreira AA (2004) Dejerine-Sottas neuropathy caused by the missense mutation PMP22 Ser72Leu. Acta Neurol Scand 110:196-199

Masuya H, Sezutsu H, Sakuraba Y, Sagai T, Hosoya M, et al. (2007) A series of ENU-induced single-base substitutions in a longrange cis-element altering Sonic hedgehog expression in the developing mouse limb bud. Genomics 89:207-214

Mburu P, Liu XZ, Walsh J, Saw D Jr, Cope MJ, et al. (1997) Mutation analysis of the mouse myosin VIIA deafness gene. Genes Funct $1: 191-203$

McKusick VA (1998) Mendelian Inheritance in Man, 12th ed. (Baltimore, MD: Johns Hopkins University Press)

McLaughlin ME, Ehrhart TL, Berson EL, Dryja TP (1995) Mutation spectrum of the gene encoding the beta subunit of rod phosphodiesterase among patients with autosomal recessive retinitis pigmentosa. Proc Natl Acad Sci U S A 92:3249-3253

Meehan TP, Tabeta K, Du X, Woodward LS, Firozi K, et al. (2006) Point mutations in the melanocortin-4 receptor cause variable obesity in mice. Mamm Genome 17:1162-1171

Meeson AP, Radford N, Shelton JM, Mammen PP, DiMaio JM, et al. (2001) Adaptive mechanisms that preserve cardiac function in mice without myoglobin. Circ Res 88:713-720

Michaud EJ, Culiat CT, Klebig ML, Barker PE, Cain KT, et al. (2005) Efficient gene-driven germ-line point mutagenesis of C57BL/6J mice. BMC Genomics 6:164 
Miyaki M, Kuroki T (2003) Role of Smad4 (DPC4) inactivation in human cancer. Biochem Biophys Res Commun 306:799-804

Munroe RJ, Ackerman SL, Schimenti JC (2004) Genomewide twogeneration screens for recessive mutations by ES cell mutagenesis. Mamm Genome 15:960-965

Ning Y, Schuller AG, Bradshaw S, Rotwein P, Ludwig T, et al. (2006) Diminished growth and enhanced glucose metabolism in triple knockout mice containing mutations of insulin-like growth factor binding protein-3, -4, and -5. Mol Endocrinol 20:21732186

Njolstad PR, Sovik O, Cuesta-Munoz A, Bjorkhaug L, Massa O, et al. (2001) Neonatal diabetes mellitus due to complete glucokinase deficiency. N Engl J Med 344:1588-1592

Nolan PM, Peters J, Strivens M, Rogers D, Hagan J, et al. (2000) A systematic, genome-wide, phenotype-driven mutagenesis programme for gene function studies in the mouse. Nat Genet 25:440-443

Noveroske JK, Hardy R, Dapper JD, Vogel H, Justice MJ (2005) A new ENU-induced allele of mouse quaking causes severe CNS dysmyelination. Mamm Genome 16:672-682

Oliver PL, Bitoun E, Clark J, Jones EL, Davies KE (2004) Mediation of Af4 protein function in the cerebellum by Siah proteins. Proc Natl Acad Sci U S A 101:14901-14906

Olson EN, Arnold HH, Rigby PW, Wold BJ (1996) Know your neighbors: three phenotypes in null mutants of the myogenic bHLH gene MRF4. Cell 85:1-4

Patrucco E, Notte A, Barberis L, Selvetella G, Maffei A, et al. (2004) PI3Kgamma modulates the cardiac response to chronic pressure overload by distinct kinase-dependent and -independent effects. Cell 118:375-387

Pazzaglia S (2006) Ptc1 heterozygous knockout mice as a model of multi-organ tumorigenesis. Cancer Lett 234:124-134

Pearce SR, Peters J, Ball S, Morgan MJ, Walker JI, et al. (1995) Sequence characterization of ENU-induced mutants of glucose phosphate isomerase in mouse. Mamm Genome 6:858-861

Porret A, Merillat AM, Guichard S, Beermann F, Hummler E (2006) Tissue-specific transgenic and knockout mice. Methods Mol Biol 337:185-205

Postic C, Shiota M, Niswender KD, Jetton TL, Chen Y, et al. (1999) Dual roles for glucokinase in glucose homeostasis as determined by liver and pancreatic beta cell-specific gene knock-outs using Cre recombinase. J Biol Chem 274:305-315

Poueymirou WT, Auerbach W, Frendewey D, Hickey JF, Escaravage JM, et al. (2007) F0 generation mice fully derived from genetargeted embryonic stem cells allowing immediate phenotypic analyses. Nat Biotechnol 25:91-99

Pretsch W, Chatterjee B, Favor J, Merkle S, Sandulache R (1998) Molecular, genetic and biochemical characterization of lactate dehydrogenase-A enzyme activity mutations in Mus musculus. Mamm Genome 9:144-149

Quwailid MM, Hugill A, Dear N, Vizor L, Wells S, et al. (2004) A gene-driven ENU-based approach to generating an allelic series in any gene. Mamm Genome 15:585-591

Rogers DC, Fisher EM, Brown SD, Peters J, Hunter AJ, et al. (1997) Behavioral and functional analysis of mouse phenotype: SHIRPA, a proposed protocol for comprehensive phenotype assessment. Mamm Genome 8:711-713

Rosenecker J, Huth S, Rudolph C (2006) Gene therapy for cystic fibrosis lung disease: current status and future perspectives. Curr Opin Mol Ther 8:439-445

Routtenberg A (1995) Knockout mouse fault lines. Nature 374:314315

Runkel F, Marquardt A, Stoeger C, Kochmann E, Simon D, et al. (2004) The dominant alopecia phenotypes Bareskin, Rexdenuded, and Reduced Coat 2 are caused by mutations in gasdermin 3. Genomics 84:824-835
Russ A, Stumm G, Augustin M, Sedlmeier R, Wattler S, et al. (2002) Random mutagenesis in the mouse as a tool in drug discovery. Drug Discov Today 7:1175-1183

Sagai T, Masuya H, Tamura M, Shimizu K, Yada Y, et al. (2004) Phylogenetic conservation of a limb-specific, cis-acting regulator of Sonic hedgehog (Shh). Mamm Genome 15:23-34

Sakuraba Y, Sezutsu H, Takahasi KR, Tsuchihashi K, Ichikawa R, et al. (2005) Molecular characterization of ENU mouse mutagenesis and archives. Biochem Biophys Res Commun 336:609616

Sandulache R, Pretsch W, Chatterjee B, Gimbel W, Graw J, et al. (1994) Molecular analysis of four lactate dehydrogenase-A mutants in the mouse. Mamm Genome 5:777-780

Sangiuolo F, Novelli G (2004) Sequence-specific modification of mouse genomic DNA mediated by gene targeting techniques. Cytogenet Genome Res 105:435-441

Shastry BS (1998) Gene disruption in mice: models of development and disease. Mol Cell Biochem 181:163-179

Sheahan S, Bellamy CO, Treanor L, Harrison DJ, Prost S (2004) Additive effect of p53, p21 and Rb deletion in triple knockout primary hepatocytes. Oncogene 23:1489-1497

Snouwaert JN, Brigman KK, Latour AM, Malouf NN, Boucher RC, et al. (1992) An animal model for cystic fibrosis made by gene targeting. Science 257:1083-1088

Solberg LC, Valdar W, Gauguier D, Nunez G, Taylor A, et al. (2006) A protocol for high-throughput phenotyping, suitable for quantitative trait analysis in mice. Mamm Genome 17:129-146

Stenson PD, Ball EV, Mort M, Phillips AD, Shiel JA, et al. (2003) Human Gene Mutation Database (HGMD): 2003 update. Hum Mutat 21:577-581

Suter U, Moskow JJ, Welcher AA, Snipes GJ, Kosaras B, et al. (1992) A leucine-to-proline mutation in the putative first transmembrane domain of the 22-kDa peripheral myelin protein in the trembler-J mouse. Proc Natl Acad Sci U S A 89:4382-4386

Thaung C, West K, Clark BJ, McKie L, Morgan JE, et al. (2002) Novel ENU-induced eye mutations in the mouse: models for human eye disease. Hum Mol Genet 11:755-767

Toye AA, Moir L, Hugill A, Bentley L, Quarterman J, et al. (2004) A new mouse model of type 2 diabetes, produced by N-ethylnitrosourea mutagenesis, is the result of a missense mutation in the glucokinase gene. Diabetes 53:1577-1583

Valentijn LJ, Baas F, Wolterman RA, Hoogendijk JE, van den Bosch $\mathrm{NH}$, et al. (1992) Identical point mutations of PMP-22 in Trembler-J mouse and Charcot-Marie-Tooth disease type 1A. Nat Genet 2:288-291

Valentijn LJ, Ouvrier RA, van den Bosch NH, Bolhuis PA, Baas F, et al. (1995) Dejerine-Sottas neuropathy is associated with a de novo PMP22 mutation. Hum Mutat 5:76-80

Vionnet N, Stoffel M, Takeda J, Yasuda K, Bell GI, et al. (1992) Nonsense mutation in the glucokinase gene causes early-onset non-insulin-dependent diabetes mellitus. Nature 356:721-722

Visscher PM, Haley CS, Thompson R (1996) Marker-assisted introgression in backcross breeding programs. Genetics 144:1923-1932

Vivian JL, Chen Y, Yee D, Schneider E, Magnuson T (2002) An allelic series of mutations in Smad2 and Smad4 identified in a genotype-based screen of N-ethyl-N- nitrosourea-mutagenized mouse embryonic stem cells. Proc Natl Acad Sci U S A 99:15542-15547

Walke DW, Han C, Shaw J, Wann E, Zambrowicz B, et al. (2001) In vivo drug target discovery: identifying the best targets from the genome. Curr Opin Biotechnol 12:626-631

Weinstein M, Yang X, Deng C (2000) Functions of mammalian Smad genes as revealed by targeted gene disruption in mice. Cytokine Growth Factor Rev 11:49-58 
Williams RW, Flaherty L, Threadgill DW (2003) The math of making mutant mice. Genes Brain Behav 2:191-200

Wu JI, Reed RB, Grabowski PJ, Artzt K (2002) Function of quaking in myelination: regulation of alternative splicing. Proc Natl Acad Sci U S A 99:4233-4238
Zambrowicz BP, Sands AT (2003) Knockouts model the 100 bestselling drugs-will they model the next 100? Nat Rev Drug Discov 2:38-51

Zingg BC, Pretsch W, Mohrenweiser HW (1995) Molecular analysis of four ENU induced triosephosphate isomerase null mutants in Mus musculus. Mutat Res 328:163-173 